\title{
Estimating Energy Conversion Efficiency of Thermoelectric Materials: Constant Property Versus Average Property Models
}

\author{
HANNAH ARMSTRONG, ${ }^{1}$ MATTHEW BOESE, ${ }^{1}$ CODY CARMICHAEL,${ }^{1}$ \\ HANNAH DIMICH ${ }^{1}$ DYLAN SEAY,${ }^{1}$ NATHAN SHEPPARD,${ }^{1}$ \\ and MATT BEEKMAN ${ }^{1,2,3}$ \\ 1.-Department of Natural Sciences, Oregon Institute of Technology, Klamath Falls, OR 97601, \\ USA. 2.-Department of Physics, California Polytechnic State University, San Luis Obispo, \\ CA 93407, USA. 3.—e-mail: mbeekman@calpoly.edu
}

Maximum thermoelectric energy conversion efficiencies are calculated using the conventional "constant property" model and the recently proposed "cumulative/average property" model (Kim et al. in Proc Natl Acad Sci USA $112: 8205,2015)$ for 18 high-performance thermoelectric materials. We find that the constant property model generally predicts higher energy conversion efficiency for nearly all materials and temperature differences studied. Although significant deviations are observed in some cases, on average the constant property model predicts an efficiency that is a factor of 1.16 larger than that predicted by the average property model, with even lower deviations for temperature differences typical of energy harvesting applications. Based on our analysis, we conclude that the conventional dimensionless figure of merit $Z T$ obtained from the constant property model, while not applicable for some materials with strongly temperature-dependent thermoelectric properties, remains a simple yet useful metric for initial evaluation and/or comparison of thermoelectric materials, provided the $Z T$ at the average temperature of projected operation, not the peak $Z T$, is used.

Key words: Thermoelectric generator, ZT, efficiency modeling, average property, constant property

\section{INTRODUCTION}

Thermoelectric generators, which directly convert heat into electrical energy with no moving parts via the Seebeck effect, continue to be developed for a variety of power generation and waste heat recovery applications. ${ }^{1}$ It has been known for more than a century $^{2}$ that the energy conversion efficiency and output power of a thermoelectric generator are directly influenced by the electrical and thermal transport properties of the materials used to fabricate it. The most widely invoked expression for

Hannah Armstrong, Matthew Boese, Cody Carmichael, Hannah Dimich, Dylan Seay and Nathan Sheppard contributed equally to this work.

(Received June 25, 2016; accepted August 17, 2016;

published online August 31, 2016) estimating the maximum energy conversion efficiency $\eta$ of a thermoelectric material is ${ }^{3,4}$

$$
\eta_{\mathrm{cp}}=\eta_{\mathrm{C}} \frac{\sqrt{1+Z T_{\mathrm{avg}}}-1}{\sqrt{1+Z T_{\mathrm{avg}}}+\frac{T_{\mathrm{C}}}{T_{\mathrm{H}}}}
$$

where $T_{\mathrm{C}}$ is the temperature of the cold side of the material, $T_{\mathrm{H}}$ is the temperature of the hot side of the material, $\eta_{\mathrm{C}}=\left(T_{\mathrm{H}}-T_{\mathrm{C}}\right) / T_{\mathrm{H}}$ is the Carnot efficiency, and $T_{\mathrm{avg}}=\left(T_{\mathrm{C}}+T_{\mathrm{H}}\right) / 2 . \quad \eta_{\mathrm{cp}}$ is a monotonically increasing function of the thermoelectric figure of merit $Z=S^{2} /(\rho \kappa)$, where $S$ is the Seebeck coefficient, $\rho$ is the electrical resistivity, and $\kappa$ is the thermal conductivity of the material. The dimensionless figure of merit $Z T$ is the most commonly used metric for evaluating the potential of a particular material for thermoelectric applications. Broadly speaking, one of the primary aims of contemporary 
thermoelectric materials research has been to find new materials with high $Z$ such that $Z T \gg 1 .^{5}$ To date, no material with $Z T>3$ is known.

Equation 1 is often referred to as the "constant property" (cp) approximation, since the model used to derive this equation (vide infra) assumes $\rho, S$, and $\kappa$ do not depend on temperature. ${ }^{3,4}$ As such, $Z$ is likewise assumed to have the same value along the length of a leg of thermoelectric material, usually taken to be equal to its value at $T_{\text {avg, }}$ i.e. $Z=Z\left(T_{\text {avg }}\right)$. However, when the temperature gradient is large, and/or one or more of the material properties are strongly temperature-dependent, the central approximation of the abovementioned constant property model is no longer valid. This has motivated the development of a variety of more sophisticated approaches that account for the temperature dependence of material properties, including numerical methods applied to inhomogeneous materials, ${ }^{6}$ iterative and finite element techniques, ${ }^{7,8}$ and reformulation in terms of reduced variables (thermoelectric compatibility). ${ }^{9}$ Calculation of the "average efficiency" based on Eq. 1 has also been suggested. ${ }^{10}$

Simulations based on finite difference methods in general produce efficiency predictions with higher accuracy than the constant property model, ${ }^{7-9}$ but they tend to be significantly more cumbersome to implement and often require specialized computing resources and/or software. Very recently, Kim et al. proposed an alternative analytical method for estimating energy conversion efficiency. ${ }^{11}$ Their analysis, based on what we will call the "average property" model (vide infra), accounts for the temperature dependence of material properties using a different expression for maximum efficiency

$$
\eta_{\mathrm{ap}}=\eta_{\mathrm{C}} \frac{\sqrt{1+(Z T)_{\mathrm{eng}}\left(\hat{\alpha} / \eta_{\mathrm{C}}-\frac{1}{2}\right)}-1}{\hat{\alpha}\left(\sqrt{1+(Z T)_{\mathrm{eng}}\left(\hat{\alpha} / \eta_{\mathrm{C}}-\frac{1}{2}\right)}+1\right)-\eta_{\mathrm{C}}},
$$

where the quantity

$$
(Z T)_{\text {eng }}=Z_{\text {eng }} \Delta T=\frac{\left(\int_{T_{\mathrm{C}}}^{T_{\mathrm{H}}} S(T) \mathrm{d} T\right)^{2}}{\int_{T_{\mathrm{C}}}^{T_{\mathrm{H}}} \rho(T) \mathrm{d} T \int_{T_{\mathrm{C}}}^{T_{\mathrm{H}}} \kappa(T) \mathrm{d} T} \Delta T
$$

is called the engineering figure of merit, and

$$
\hat{\alpha}=\frac{S\left(T_{H}\right) \Delta T}{\int_{T_{C}}^{T_{H}} S(T) \mathrm{d} T}
$$

is called the intensity factor of the Thomson effect. ${ }^{11}$

For large temperature differences and/or materials with strongly temperature-dependent transport properties, e.g. the binary compounds $\mathrm{SnSe}^{12}$ and $\mathrm{In}_{4} \mathrm{Se}_{3-x},{ }^{13} \mathrm{Kim}$ et al. demonstrated that Eq. 1 can significantly overestimate the energy conversion efficiency in comparison to predictions from finite difference numerical simulations. ${ }^{11}$ In contrast, Eqs. 2-4 provided an estimate of the energy conversion efficiency in closer agreement with simulation. Based on these observations, the authors called into question the common practice of using the traditional dimensionless figure of merit as a metric for evaluating thermoelectric performance of a material, and suggested $(Z T)_{\text {eng }}$ is a more reliable metric. Nonetheless, for other materials having properties with less pronounced temperature dependence, the calculated efficiencies from the conventional constant property method and average property method show reasonable agreement. ${ }^{11}$ In the present work, we have further evaluated the constant property and average property models by comparison of the corresponding predicted energy conversion efficiencies for 18 high performance thermoelectric materials for a range of operating temperature differences. We find that although the constant property model (Eq. 1) typically predicts higher energy conversion efficiency in nearly all cases, the maximum deviation between the two methods is less than $15 \%$ for the majority of the materials evaluated. Although in general $(Z T)_{\text {eng }}$ provides a more conservative metric, we conclude that the average $Z T$ of material for a given temperature difference can still be used as a reasonably reliable metric for comparison and evaluation of most materials, provided the temperature dependence of the individual thermoelectric properties is not too pronounced.

\section{MODELS AND METHODS}

Expressions for energy conversion efficiency for both the constant property ${ }^{3,4}$ and average property ${ }^{11}$ methods are derived by considering a single homogenous thermoelectric leg (Fig. 1) having electrical resistance $R$, thermal conductance $K$, and Seebeck coefficient $S$. Taking into account the rates of heat transfer originating from thermal conduction $Q_{\kappa}$, Peltier effect $Q_{\pi}$, and Joule heating $Q_{\rho}$, the energy conversion efficiency is equal to the output power delivered to the load divided by the net rate of heat input at the hot side (see Fig. 1),

$$
\begin{aligned}
\eta & =\frac{P_{\text {out }}}{Q_{\text {in }}}=\frac{I^{2} R_{\mathrm{L}}}{I T_{\mathrm{H}} S\left(T_{\mathrm{H}}\right)+K \Delta T-\frac{1}{2} I^{2} R} \\
& =\frac{\frac{\Delta V_{\text {oc }}^{2}}{R} \frac{M}{(1+M)^{2}}}{I T_{\mathrm{H}} S\left(T_{\mathrm{H}}\right)+K \Delta T-\frac{1}{2} I^{2} R}
\end{aligned}
$$

The last equality follows from the fact that the current that flows in the circuit is $I=\Delta V_{\mathrm{oc}} /\left(R+R_{\mathrm{L}}\right)$, where $\Delta V_{\text {oc }}=-S \Delta T$ is the open circuit thermal emf, i.e. the Seebeck voltage, and $R_{\mathrm{L}}$ is the load resistance. Here we have defined the quantity $M=R_{\mathrm{L}} / R$ as has been done previously. ${ }^{3,4,14}$ The electrical resistance and thermal conductance of the leg are $R=\rho l / A$ and $K=\kappa A / l$, respectively, where $l$ is the length of the leg and $A$ is its cross-sectional area.

The constant property model and average property model both have Eq. 5 as their basis. The constant property model presumes the properties of 


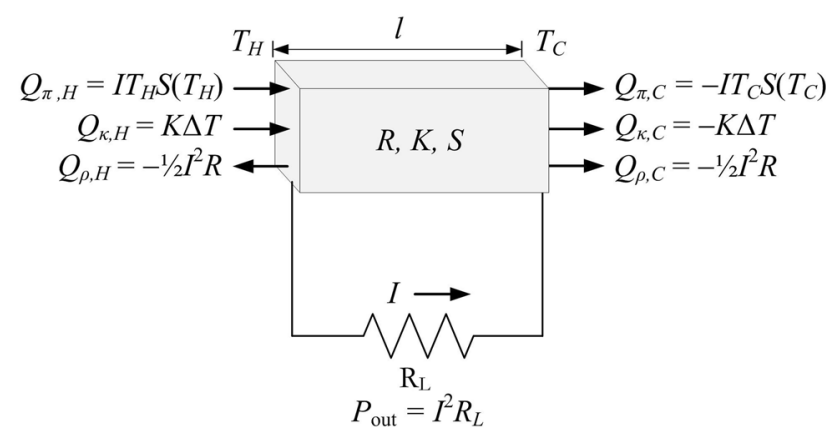

Fig. 1. Schematic showing a single $n$-type thermoelectric leg of length I connected to a load. $R$ is the electrical resistance of the leg, $K$ is the thermal conductance of the leg, $S$ is the Seebeck coefficient of the leg, $I$ is the (conventional) electrical current, $R_{L}$ is the electrical resistance of the load, $P_{\text {out }}$ is the electrical power delivered to the load, and the $Q_{i, j}$ are the rates of heat transfer into/out of the leg at the hot $(j=H)$ and cold $(j=C)$ sides due to the Peltier effect $(i=\pi)$, irreversible thermal conduction $(i=\kappa)$, and joule heating $(i=\rho)$.

the material, namely $\rho, S$, and $\kappa$, are not temperature-dependent and have the same value along the entire length of the leg. ${ }^{3,4,14}$ Under this assumption, maximizing Eq. 5 with respect to the resistance ratio $M$ yields the condition $M=\sqrt{1+Z T_{\text {avg }}}$, and the maximum efficiency is given by Eq. 1 . The experimental values of $\rho, S$, and $\kappa$ (and, therefore, $Z$ ) used in the constant property model are typically chosen to be the values of each of these properties at the average temperature, $T_{\mathrm{avg}}=\left(T_{\mathrm{C}}+T_{\mathrm{H}}\right) / 2{ }^{3,4,14}$

The basis of the average property model of Kim et al. is similar to that of the constant property model in the respect that single values for $\rho, S$, and $\kappa$ are still used in Eq. 5. However, these values are taken to be the average values of the properties in the temperature range $T_{\mathrm{C}}$ to $T_{\mathrm{H}}$, i.e. ${ }^{11}$

$$
\begin{gathered}
\rho=\rho_{\text {avg }}=\frac{1}{\Delta T} \int_{T_{\mathrm{C}}}^{T_{\mathrm{H}}} \rho(T) \mathrm{d} T \\
S=S_{\text {avg }}=\frac{1}{\Delta T} \int_{T_{\mathrm{C}}}^{T_{\mathrm{H}}} S(T) \mathrm{d} T \\
\kappa=\kappa_{\text {avg }}=\frac{1}{\Delta T} \int_{T_{\mathrm{C}}}^{T_{\mathrm{H}}} \kappa(T) \mathrm{d} T
\end{gathered}
$$

The values obtained from Eqs. 6-8 will in general differ from the values of the properties at $T=T_{\text {avg }}$, therefore, resulting in a different predicted efficiency. ${ }^{11}$ In addition, although it is assumed that $S\left(T_{\mathrm{avg}}\right)=S\left(T_{\mathrm{H}}\right)$ in the constant property model (a key simplifying approximation), in general $S_{\text {avg }} \neq$ $S\left(T_{\mathrm{H}}\right)$ in the average property model. Inserting these definitions into Eq. 5 and again maximizing with respect to $M$, one obtains Eqs. $2-4 .^{11}$
Two points are worthwhile to note. First, neither the constant property nor the average property model predict efficiencies representative of actual experimental device efficiencies, since both models neglect parasitic losses from contact resistances, heat transfer due to radiation, temperature dependence of the thermoelectric compatibility factor, etc. ${ }^{3,4,9,14,15}$ Second, both models also neglect the Thomson heat, which can result in either under- or over-predicted relative efficiency values depending on the sign and magnitude of the Thomson coefficient. ${ }^{11} \mathrm{Kim}$ et al. provided further more sophisticated analysis that accounts for the Thomson heat, the effect of which can be significant if $S$ is strongly temperature dependent. ${ }^{11}$ It was shown that inclusion of the Thomson effect generally produced the best agreement with numerical simulation, however it increases the complexity of the calculation. Since both models, Eqs. 1 and 2, are expected to consistently over-predict the efficiency when compared to the experimental efficiency of an actual device, ${ }^{3,4,9,14,15}$ the utility of the models lies in their ability to provide simple and consistent metrics for the comparison and evaluation of the potential of new materials for thermoelectric applications.

Experimental $\rho, S$, and $\kappa$ data for the 18 materials evaluated in the present study were extracted from the respective original publications ${ }^{12,13,16-31}$ using the freely available software WebPlotDigitizer. ${ }^{32}$ When using the average property model, values for Eqs. 6-8 were computed via numerical integration using Simpson's rule applied to the extracted experimental data.

\section{RESULTS AND DISCUSSION}

We first reproduced the calculations of Kim et al. ${ }^{11}$ for the compounds SnSe, ${ }^{12} \operatorname{In}_{4} \mathrm{Se}_{3-x},{ }^{13}$ and $\mathrm{Hf}_{0.19} \mathrm{Zr}_{0.76} \mathrm{Ti}_{0.05} \mathrm{CoSb}_{0.8} \mathrm{Sn}_{0.2 .}{ }^{24}$ The $Z T$ values (calculated from the extracted transport coefficients) as a function of temperature for the three materials are shown in Fig. 2a; the calculated efficiencies $\eta$ $\left(T_{\mathrm{C}}=373 \mathrm{~K}\right)$ based on Eqs. 1 and 2 are shown in Fig. 2b. While the calculated efficiencies for SnSe and $\mathrm{Hf}_{0.19} \mathrm{Zr}_{0.76} \mathrm{Ti}_{0.05} \mathrm{CoSb}_{0.8} \mathrm{Sn}_{0.2}$ (half-Heusler) show good agreement with the previous calculations of Kim et al., ${ }^{11}$ both calculated efficiencies (Eqs. 1 and 2) for $\mathrm{In}_{4} \mathrm{Se}_{3-x}$ are significantly higher than those reported in Ref. 11 . We could not identify with certainty the source of the discrepancy, but it may be due to a mislabeling of the horizontal axis in Fig. $2 \mathrm{~b}$ of Ref. 13, from which the transport data were extracted. We are nevertheless confident in our data as the $Z T$ values calculated from the extracted transport coefficients are in very good agreement with those reported in Ref. 13. Regardless, in general agreement with the conclusions of Kim et al., it is apparent from Fig. 2b that Eq. 1 significantly over-predicts $\eta$ for $\mathrm{SnSe}$ and $\mathrm{In}_{4} \mathrm{Se}_{3-x}$ in comparison to the average property model at higher temperature differences, with maximum 

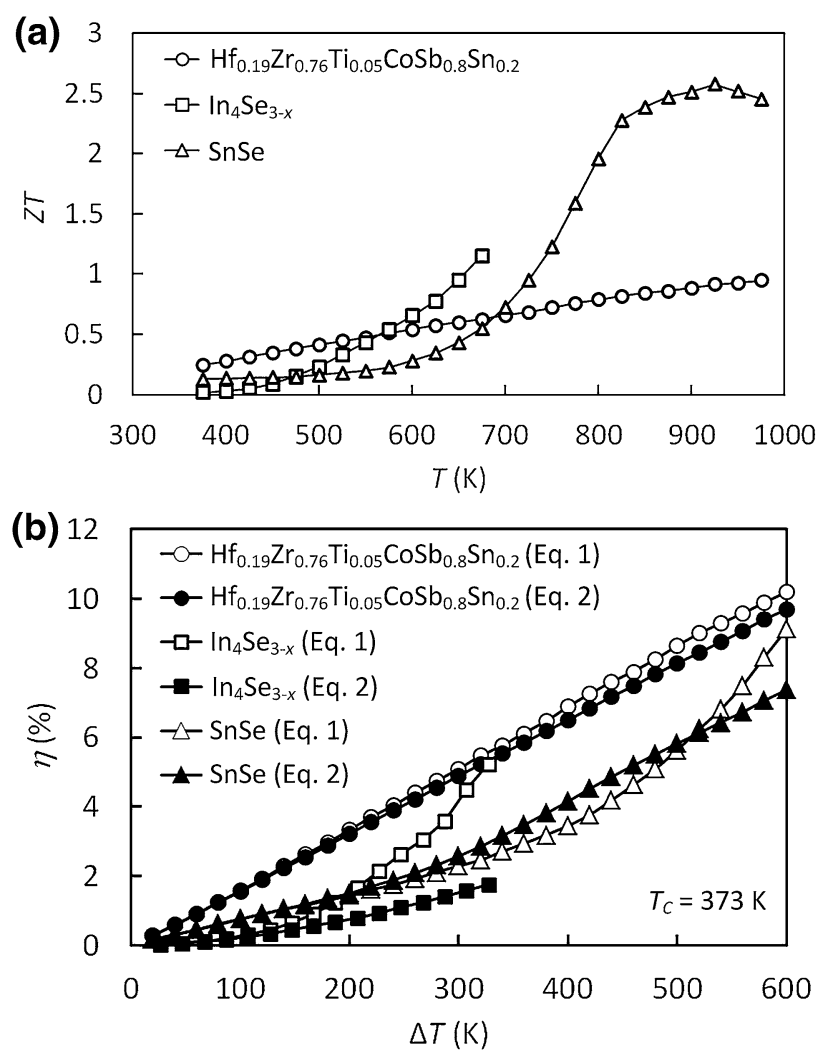

Fig. 2. (a) $Z T$ as a function of temperature for $S n S e,,^{12} \ln _{4} \mathrm{Se}_{3-x},{ }^{13}$ and $\mathrm{Hf}_{0.19} \mathrm{Zr}_{0.76} \mathrm{Ti}_{0.05} \mathrm{CoSb}_{0.8} \mathrm{Sn}_{0.2 .}{ }^{24}$ (b) Efficiency as function of temperature difference $\left(T_{C}=373 \mathrm{~K}\right)$ calculated by Eqs. 1 and 2 for SnSe, $\mathrm{In}_{4} \mathrm{Se}_{3-x}$, and $\mathrm{Hf}_{0.19} \mathrm{Zr}_{0.76} \mathrm{Ti}_{0.05} \mathrm{CoSb}_{0.8} \mathrm{Sn}_{0.2}$.

percent differences $\delta_{\max }\left(\delta=100 \% \times \mid \eta_{\mathrm{cp}}-\eta_{\mathrm{ap}} \mathrm{I} /\right.$ $\left.\eta_{\mathrm{ap}}\right)$ of $24 \%$ and $190 \%$. The relative over-prediction of the constant property model can be attributed to the strong temperature dependence of the thermoelectric properties for these two materials. Based on this observation, Kim et al. called into question the use of the constant property model and traditional definition of $Z T$ in evaluating the potential of thermoelectric materials. ${ }^{11}$ In contrast, the two methods, Eqs. 1 and 2, predict comparable efficiencies for the half-Heusler compound for all $\Delta T$ and a maximum deviation between the models of only $4 \%$. Also, in spite of $\operatorname{In}_{4-x} \mathrm{Se}_{3}$ and SnSe having significantly higher peak $Z T$ values, both Eqs. 1 and 2 agree in their prediction that the half-Heusler compound should have the higher energy conversion efficiency over the entire range of $\Delta T$ evaluated.

To obtain a more comprehensive comparison of the constant property and average property models, Eqs. 1 and 2 were used to calculate the energy conversion efficiency as a function of temperature difference for 15 additional materials having peak $Z T \approx 1$ or higher. ${ }^{12,13,16-31}$ The selected materials represent a variety of different material classes, including chalcogenides, skutterudites, intermetallic clathrates, oxides, antimonides, half-heuslers,
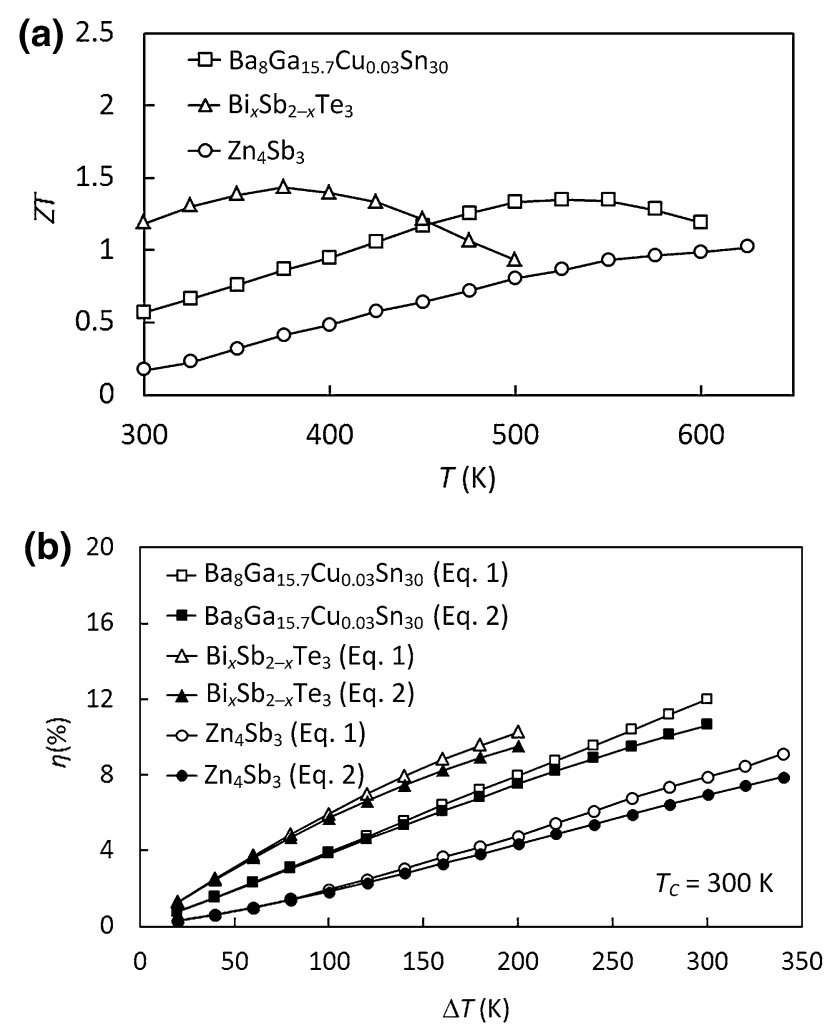

Fig. 3. (a) $Z T$ as a function of temperature for $B a_{8} G_{15.7-}$ $\mathrm{Cu}_{0.03} \mathrm{Sn}_{30},{ }^{17} \mathrm{Bi}_{x} \mathrm{Sb}_{2-x} \mathrm{Te}_{3},{ }^{19}$ and $\mathrm{Zn}_{4} \mathrm{Sb}_{3}{ }^{31}$ (b) Efficiency as function of temperature difference $\left(T_{\mathrm{C}}=300 \mathrm{~K}\right)$ calculated by Eqs. 1 and 2 for $\mathrm{Ba}_{8} \mathrm{Ga}_{15.7} \mathrm{Cu}_{0.03} \mathrm{Sn}_{30}, \mathrm{Bi}_{x} \mathrm{Sb}_{2-x} \mathrm{Te}_{3}$, and $\mathrm{Zn}_{4} \mathrm{Sb}_{3}$.

and silicides, evaluated at various potential temperature ranges of operation. The results are shown in Figs. 3-8 and in Table I. In nearly all cases, it was found that Eq. 1 over-predicts the energy conversion efficiency in comparison to Eq. 2 over the entire range of temperature differences, indicating Eq. 2 consistently provides a more conservative estimate of the efficiency. The only exceptions observed were $\mathrm{Bi}_{2} \mathrm{Sr}_{2} \mathrm{Co}_{2} \mathrm{O}_{y}$ (Fig. 5) and $\mathrm{SnSe}$ (Fig. 2), each of which showed a range of $\Delta T$ for which Eq. 2 over-predicts $\eta$ relative to Eq. 1, which we attribute to atypical temperature dependencies of the electrical transport properties of these materials. In particular, in $\mathrm{Bi}_{2} \mathrm{Sr}_{2} \mathrm{Co}_{2} \mathrm{O}_{y}$ the curvature $\mathrm{d}^{2} S / \mathrm{d} T^{2}$ changes sign as $T$ increases, whereas in SnSe $\mathrm{d}^{2} \rho / \mathrm{d} T^{2}$ changes sign as $T$ increases. The sign of the curvature of the transport properties with respect to temperature has an influence on whether the value of the property at $T_{\text {avg }}$ is greater or less than the averaged transport property (Eqs. 6-8). For all other materials studied, the deviation $\delta$ between the two methods typically increases monotonically with increasing $\Delta T$. We note that the majority of the 18 materials studied have $\delta_{\max }$ (maximum percent difference between calculated efficiencies, which typically occurs at the maximum $\Delta T$ ) less than $15 \%$ (see Table I and Fig. 8). As shown in Table I, the five exceptions (about one quarter of 

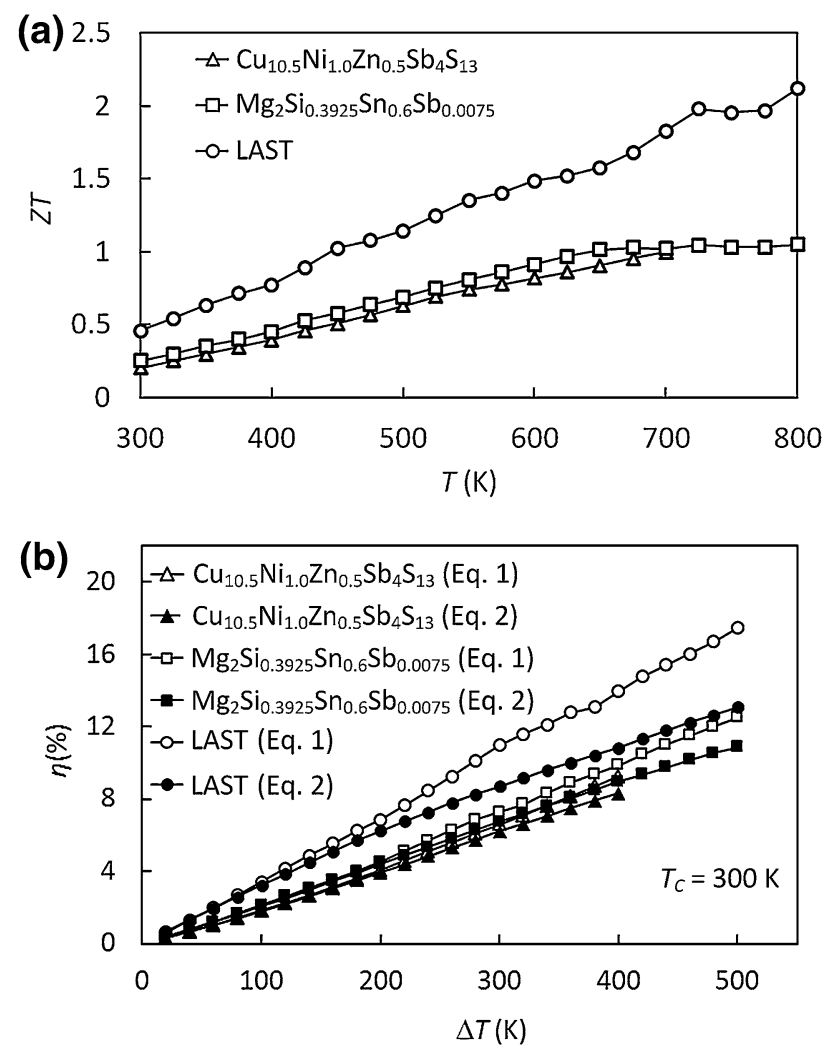

Fig. 4. (a) $Z T$ as a function of temperature for $\mathrm{AgPb}_{18} \mathrm{SbTe}_{20}$ (LAST), ${ }^{16} \mathrm{Mg}_{2} \mathrm{Si}_{0.3925} \mathrm{Sn}_{0.6} \mathrm{Sb}_{0.0075},{ }^{26}$ and $\mathrm{Cu}_{10.5} \mathrm{Ni}_{1.0} \mathrm{Zn}_{0.5} \mathrm{Sb}_{4} \mathrm{~S}_{13}{ }_{21}$ (b) Efficiency as function of temperature difference $\left(T_{C}=300 \mathrm{~K}\right)$ calculated by Eqs. 1 and 2 for $\mathrm{AgPb}_{18} \mathrm{SbTe}_{20}$, $\mathrm{Mg}_{2} \mathrm{Si}_{0.3925} \mathrm{Sn}_{0.6} \mathrm{Sb}_{0.0075}$, and $\mathrm{Cu}_{10.5} \mathrm{Ni}_{1.0} \mathrm{Zn}_{0.5} \mathrm{Sb}_{4} \mathrm{~S}_{13}$.

the materials studied) were $\mathrm{AgPb}_{18} \mathrm{SbTe}_{20}\left(\delta_{\max }=\right.$ $33.6 \%), \quad \mathrm{In}_{4} \mathrm{Se}_{2.35} \quad\left(\delta_{\max }=190 \%\right), \quad \mathrm{PbSe}_{0.15} \mathrm{Te}_{0.85}$ $\left(\delta_{\max }=37.0 \%\right)$, SnSe $\left(\delta_{\max }=24.0 \%\right)$, and SrTe-PbTe $\left(\delta_{\max }=32.8 \%\right)$. Interestingly, four of these five materials with the largest deviations between the methods are materials based on group 14 chalcogenides. Excluding the outlier $\operatorname{In}_{4} \mathrm{Se}_{2.35}$, the constant property model predicts energy conversion efficiencies that are on average a factor of 1.16 larger than the efficiency predicted by the average property model. We also find additional examples where maximum (peak) ZT is not a good predictor of thermoelectric performance. For example, although SrTe-PbTe has a $Z T$ of 2.0 and $\mathrm{Ba}_{0.08} \mathrm{La}_{0.05} \mathrm{Yb}_{0.04}$ $\mathrm{Co}_{4} \mathrm{Sb}_{12}$ has a $Z T$ of 1.5 at $800 \mathrm{~K}$, Eq. 1 predicts they will have similar efficiencies for $\Delta T=500 \mathrm{~K}$ $\left(T_{C}=300 \mathrm{~K}\right)$, and Eq. 2 predicts the lower peak $Z T \mathrm{Ba}_{0.08} \mathrm{La}_{0.05} \mathrm{Yb}_{0.04} \mathrm{Co}_{4} \mathrm{Sb}_{12}$ will have a substantially higher efficiency than SrTe-PbTe. Although SrTe-PbTe has a much higher peak $Z T$, $\mathrm{Ba}_{0.08} \mathrm{La}_{0.05} \mathrm{Yb}_{0.04} \mathrm{Co}_{4} \mathrm{Sb}_{12}$ has better thermoelectric properties on average (Fig. 5).

Reviewing the $Z T$ curves for the materials studied, it appears that the temperature dependence (rate of change) of $Z T$ alone does not appear to be a good indicator of whether the two models will produce significantly different efficiencies. One
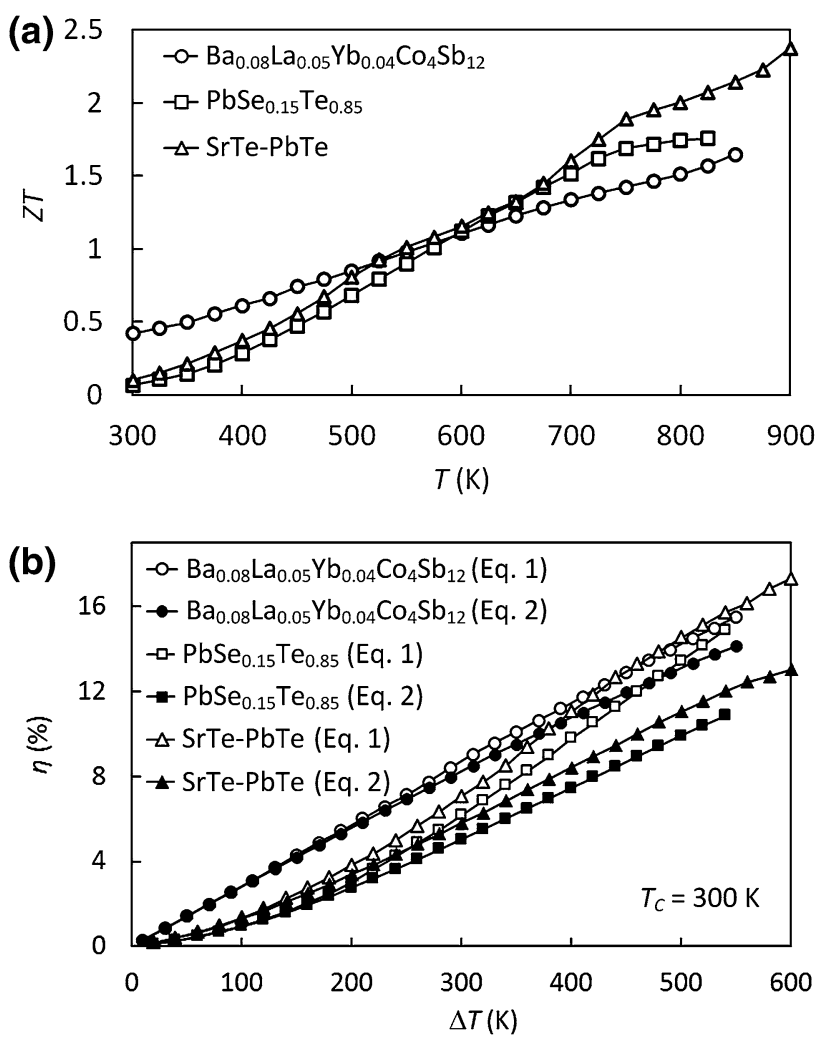

Fig. 5. (a) $Z T$ as a function of temperature for $\mathrm{Ba}_{0.08}$ $\mathrm{La}_{0.05} \mathrm{Yb}_{0.04} \mathrm{Co}_{4} \mathrm{Sb}_{12},{ }^{18} \mathrm{PbSe}_{0.15} \mathrm{Te}_{0.85},{ }^{27}$ and $\mathrm{SrTe} \mathrm{PbTe}{ }^{29}$ (b) Efficiency as function of temperature difference $\left(T_{C}=300 \mathrm{~K}\right)$ calculated by Eqs. 1 and 2 for $\mathrm{Ba}_{0.08} \mathrm{La}_{0.05} \mathrm{Yb}_{0.04} \mathrm{Co}_{4} \mathrm{Sb}_{12}, \mathrm{PbSe}_{0.15} \mathrm{Te}_{0.85}$, and SrTe-PbTe.

must, therefore, examine the temperature dependence of the individual transport properties to determine if the average values should be calculated. Evaluating the individual percent differences between the transport property values used in the two models, e.g. $\rho\left(T_{\mathrm{avg}}\right)$ and $\rho_{\text {avg }}$, the source of the discrepancy can be identified for each material. However, we did not find any one particular transport property to be consistently the root cause of the deviation between the two methods for the materials studied.

Several assessments ${ }^{1,4,5,10,33}$ of the potential of thermoelectric technology have concluded that $Z T$ values in the range of $2-3$ or higher could enable significantly broader use of thermoelectric technology in waste heat recovery and other energy conversion applications. This is illustrated in Fig. 9, which plots the maximum efficiency calculated from the constant property model as a function of $Z T_{\text {avg }}$ (Eq. 1) for $T_{\mathrm{C}}=300 \mathrm{~K}$ and $T_{\mathrm{H}}=800 \mathrm{~K}$, temperatures typical of waste heat recovery applications. ${ }^{10} \mathrm{~A} Z T$ value of 1 results in an efficiency of approximately $15 \%$, whereas $Z T$ values of 2 and 3 result in substantially higher efficiencies of approximately $22 \%$ and $26 \%$, respectively. It is important, however, to remember that $Z T$ in this model is the average $Z T$ for the operating temperature range, 

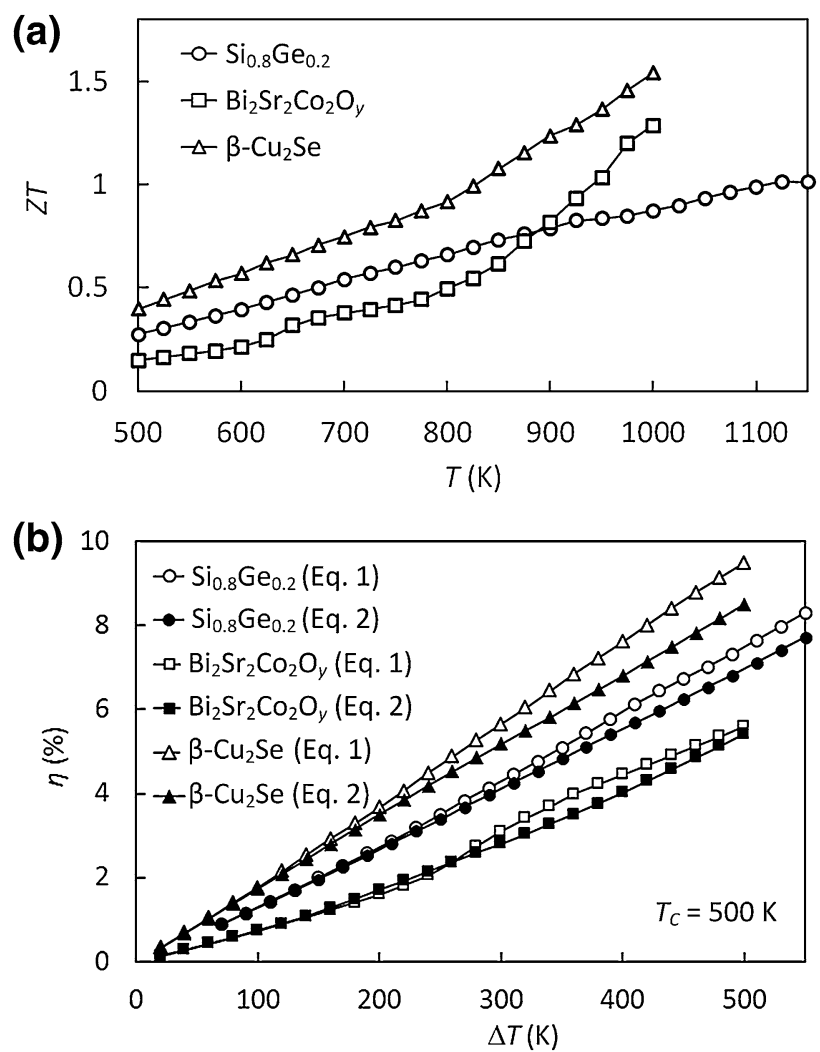

Fig. 6. (a) $Z T$ as a function of temperature for $\mathrm{Si}_{0.8} \mathrm{Ge}_{0.2},{ }^{28} \mathrm{Bi}_{2} \mathrm{Sr}_{2}$ $\mathrm{CO}_{2} \mathrm{O}_{y}{ }^{20}$ and $\mathrm{Cu}_{2} \mathrm{Se}^{22}$ (b) Efficiency as function of temperature difference $\left(T_{C}=500 \mathrm{~K}\right)$ calculated by Eqs. 1 and 2 for $\mathrm{Si}_{0.8} \mathrm{Ge}_{0.2}$, $\mathrm{Bi}_{2} \mathrm{Sr}_{2} \mathrm{Co}_{2} \mathrm{O}_{y}$, and $\mathrm{Cu}_{2} \mathrm{Se}$.

not peak ZT. As shown in Table I, nearly all materials studied here have average $Z T$ that is significantly less than the peak $Z T$, because $Z T$ typically peaks near or above $T_{H}$. The one exception in Table $\mathrm{I}$ is $\mathrm{Bi}_{x} \mathrm{Sb}_{2-x} \mathrm{Te}_{3}$, which has equivalent average and peak $Z T$ due to the atypical feature of the maximum being located near the midpoint of the measured temperature range. Although considerable emphasis is placed on achieving high peak or maximum $Z T$ in contemporary thermoelectric materials research literature, ${ }^{12,13,16-31}$ it is not as important as achieving high average $Z T$. Furthermore, the need for high average $Z T$ can place greater expectations on the corresponding requisite value of peak or maximum $Z T$. For example, assuming a linear temperature dependence of $Z T$ on $T$, i.e. $Z$ independent of temperature, and $Z T=0.25$ at $T_{\mathrm{C}}=300 \mathrm{~K}$, a peak value of $Z T=3.75$ at $T_{\mathrm{H}}=800 \mathrm{~K}$ is required for an average $Z T$ value of 2 , corresponding to an estimated efficiency of approximately $22 \%$ (Fig. 2). No known material has a peak $Z T$ value this high. Moreover, arbitrarily using peak $Z T$ instead of $Z\left(T_{\text {avg }}\right) T_{\text {avg }}$ in Eq. 1, independent of the chosen operating temperatures, can lead to excessive overestimation of the ideal energy conversion efficiency. ${ }^{13}$ Indeed, this relatively common conceptual oversight in evaluating
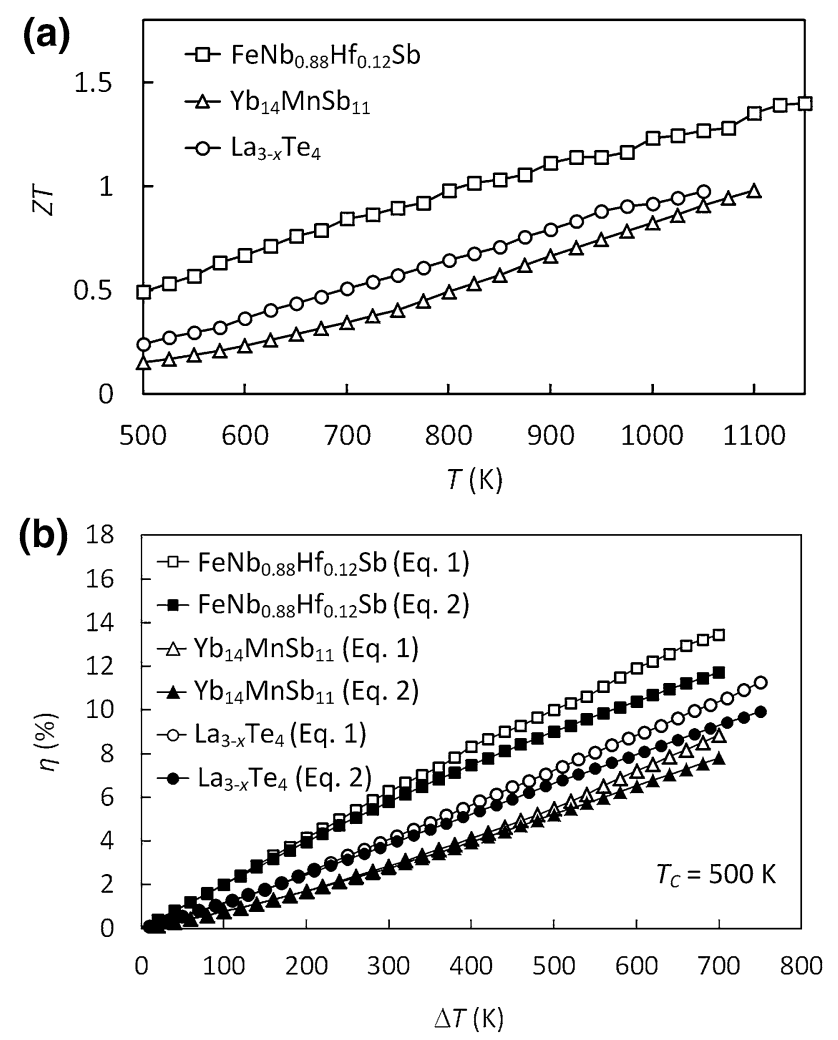

Fig. 7. (a) $Z T$ as a function of temperature for $\mathrm{FeNb}_{0.88} \mathrm{Hf}_{0.12} \mathrm{Sb},{ }^{23}$ $\mathrm{Yb}_{14} \mathrm{MnSb}_{11}{ }^{30}$ and $\mathrm{La}_{3-x} \mathrm{Te}_{4}{ }^{25}$ (b) Efficiency as function of temperature difference $\left(T_{\mathrm{C}}=500 \mathrm{~K}\right)$ calculated by Eqs. 1 and 2 for $\mathrm{FeNb}_{0.88} \mathrm{Hf}_{0.12} \mathrm{Sb}, \mathrm{Yb}_{14} \mathrm{MnSb}_{11}$, and $\mathrm{La}_{3-x} \mathrm{Te}_{4}$.

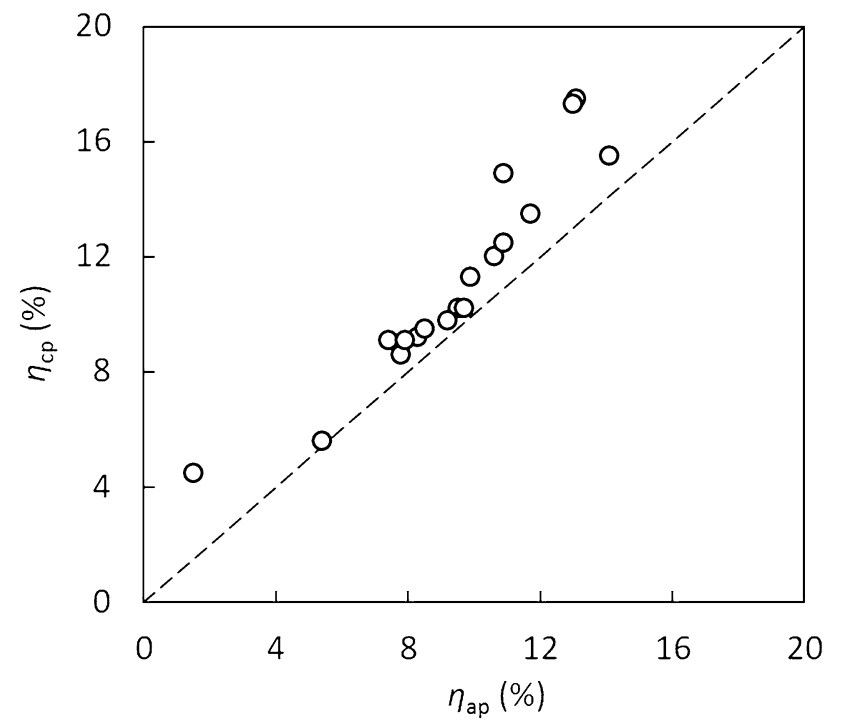

Fig. 8. Calculated maximum thermoelectric energy conversion efficiency from the constant property model $\left(\eta_{\mathrm{cp}}\right)$ plotted versus the corresponding efficiency calculated from the average property model $\left(\eta_{\mathrm{ap}}\right)$, corresponding to the maximum temperature difference. The dashed line indicates perfect agreement between the two values.

and comparing the potential of new materials can produce a more significant over-estimation of a material's potential for thermoelectric applications 
Table I. Results from efficiency calculations using Eqs. 1 and 2 for 18 thermoelectric materials

\begin{tabular}{|c|c|c|c|c|c|c|c|}
\hline $\begin{array}{l}\text { Composition (material } \\
\text { class, carrier type) }\end{array}$ & $\begin{array}{l}\boldsymbol{T}_{\mathbf{C}} \\
T_{\mathrm{H}}\end{array}$ & $(Z T)_{\max }$ & $Z\left(T_{\text {avg }}\right) T_{\text {avg }}$ & $\eta_{\text {ap }}(\%)$ & $\eta_{\mathrm{cp}}(\%)$ & $\delta_{\max }(\%)$ & Ref. \\
\hline $\begin{array}{l}\mathrm{AgPb}_{18} \mathrm{SbTe}_{20} \\
\text { (chalcogenide, } n \text {-type) }\end{array}$ & $\begin{array}{l}300 \mathrm{~K} \\
800 \mathrm{~K}\end{array}$ & 2.1 & 1.4 & 13.1 & 17.5 & 33.6 & 16 \\
\hline $\begin{array}{l}\mathrm{Ba}_{8} \mathrm{Ga}_{15.7} \mathrm{Cu}_{0.03} \mathrm{Sn}_{30} \\
\text { (clathrate, } n \text {-type) }\end{array}$ & $\begin{array}{l}300 \mathrm{~K} \\
600 \mathrm{~K}\end{array}$ & 1.4 & 1.2 & 10.6 & 12.0 & 12.7 & 17 \\
\hline $\begin{array}{l}\mathrm{Ba}_{0.08} \mathrm{La}_{0.05} \mathrm{Yb}_{0.04} \mathrm{Co}_{4} \mathrm{Sb}_{12} \\
\text { (skutterudite, } n \text {-type) }\end{array}$ & $\begin{array}{l}300 \mathrm{~K} \\
850 \mathrm{~K}\end{array}$ & 1.6 & 1.0 & 14.1 & 15.5 & 10.0 & 18 \\
\hline $\begin{array}{l}\mathrm{Bi}_{x} \mathrm{Sb}_{2-x} \mathrm{Te}_{3} \\
\text { (chalcogenide, } p \text {-type) }\end{array}$ & $\begin{array}{l}300 \mathrm{~K} \\
500 \mathrm{~K}\end{array}$ & 1.4 & 1.4 & 9.5 & 10.2 & 7.7 & 19 \\
\hline $\begin{array}{l}\mathrm{Bi}_{2} \mathrm{Sr}_{2} \mathrm{Co}_{2} \mathrm{O}_{y} \\
\text { (oxide, } p \text {-type) }\end{array}$ & $\begin{array}{c}500 \mathrm{~K} \\
1000 \mathrm{~K}\end{array}$ & 1.3 & 0.41 & 5.4 & 5.6 & 3.0 & 20 \\
\hline $\begin{array}{l}\mathrm{Cu}_{10.5} \mathrm{Ni}_{1.0} \mathrm{Zn}_{0.5} \mathrm{Sb}_{4} \mathrm{~S}_{13} \\
\text { (tetrahedrite, } p \text {-type) }\end{array}$ & $\begin{array}{l}300 \mathrm{~K} \\
700 \mathrm{~K}\end{array}$ & 1.0 & 0.63 & 8.3 & 9.2 & 11.0 & 21 \\
\hline $\begin{array}{l}\beta \text { - } \mathrm{Cu}_{2} \mathrm{Se} \\
\text { (chalcodenide, } p \text {-type) }\end{array}$ & $\begin{array}{c}500 \mathrm{~K} \\
1000 \mathrm{~K}\end{array}$ & 1.5 & 0.83 & 8.5 & 9.5 & 11.5 & 22 \\
\hline $\begin{array}{l}\mathrm{FeNb}_{0.88} \mathrm{Hf}_{0.12} \mathrm{Sb} \\
\text { (half-Heusler, } p \text {-type) }\end{array}$ & $\begin{array}{c}500 \mathrm{~K} \\
1200 \mathrm{~K}\end{array}$ & 1.5 & 1.0 & 11.7 & 13.5 & 14.7 & 23 \\
\hline $\begin{array}{l}\mathrm{In}_{4} \mathrm{Se}_{2.35} \\
\text { (chalcogenide, } n \text {-type) }\end{array}$ & $\begin{array}{l}373 \mathrm{~K} \\
673 \mathrm{~K}\end{array}$ & 1.2 & 0.33 & 1.5 & 4.5 & 190 & 13 \\
\hline $\begin{array}{l}\mathrm{Hf}_{0.19} \mathrm{Zr}_{0.76} \mathrm{Ti}_{0.05} \mathrm{CoSb} \\
\text { (half-Heulser, } p \text {-type) }\end{array}$ & $\begin{array}{l}373 \mathrm{~K} \\
972 \mathrm{~K}\end{array}$ & 1.0 & 0.63 & 9.7 & 10.2 & 5.2 & 24 \\
\hline $\begin{array}{l}\mathrm{La}_{3-x} \mathrm{Te}_{4} \\
\text { (chalcogenide, } n \text {-type) }\end{array}$ & $\begin{array}{l}500 \mathrm{~K} \\
1250 \mathrm{~K}\end{array}$ & 1.2 & 0.75 & 9.9 & 11.3 & 13.6 & 25 \\
\hline $\begin{array}{l}\mathrm{Mg}_{2} \mathrm{Si}_{0.3925} \mathrm{Sn}_{0.6} \mathrm{Sb}_{0.0075} \\
\text { (antiflourite silicide, } n \text {-type) }\end{array}$ & $\begin{array}{l}300 \mathrm{~K} \\
800 \mathrm{~K}\end{array}$ & 1.1 & 0.81 & 10.9 & 12.5 & 14.9 & 26 \\
\hline $\begin{array}{l}\mathrm{PbSe}_{0.15} \mathrm{Te}_{0.85} \\
\text { (chalcogenide, } p \text {-type) }\end{array}$ & $\begin{array}{l}300 \mathrm{~K} \\
840 \mathrm{~K}\end{array}$ & 1.8 & 0.99 & 10.9 & 14.9 & 37.0 & 27 \\
\hline $\begin{array}{l}\mathrm{Si}_{0.8} \mathrm{Ge}_{0.2} \\
\text { (diamond-like, } n \text {-type) }\end{array}$ & $\begin{array}{l}500 \mathrm{~K} \\
1150 \mathrm{~K}\end{array}$ & 1.0 & 0.68 & 9.2 & 9.8 & 6.8 & 28 \\
\hline $\begin{array}{l}\text { SnSe } \\
\text { (chalcogenide, } p \text {-type) }\end{array}$ & $\begin{array}{l}373 \mathrm{~K} \\
973 \mathrm{~K}\end{array}$ & 2.6 & 0.55 & 7.4 & 9.1 & 24.0 & 12 \\
\hline $\begin{array}{l}\text { SrTe-PbTe } \\
\text { (chalcogenide, } p \text {-type) }\end{array}$ & $\begin{array}{l}300 \mathrm{~K} \\
900 \mathrm{~K}\end{array}$ & 2.4 & 1.2 & 13.0 & 17.3 & 32.8 & 29 \\
\hline $\begin{array}{l}\mathrm{Yb}_{14} \mathrm{MnSb}_{11} \\
\text { (antimonide, } p \text {-type) }\end{array}$ & $\begin{array}{l}500 \mathrm{~K} \\
1200 \mathrm{~K}\end{array}$ & 1.0 & 0.57 & 7.8 & 8.6 & 13.4 & 30 \\
\hline $\begin{array}{l}\mathrm{Zn}_{4} \mathrm{Sb}_{3} \\
\text { (antimonide, } p \text {-type) }\end{array}$ & $\begin{array}{l}300 \mathrm{~K} \\
640 \mathrm{~K}\end{array}$ & 1.1 & 0.70 & 7.9 & 9.1 & 15.5 & 31 \\
\hline
\end{tabular}

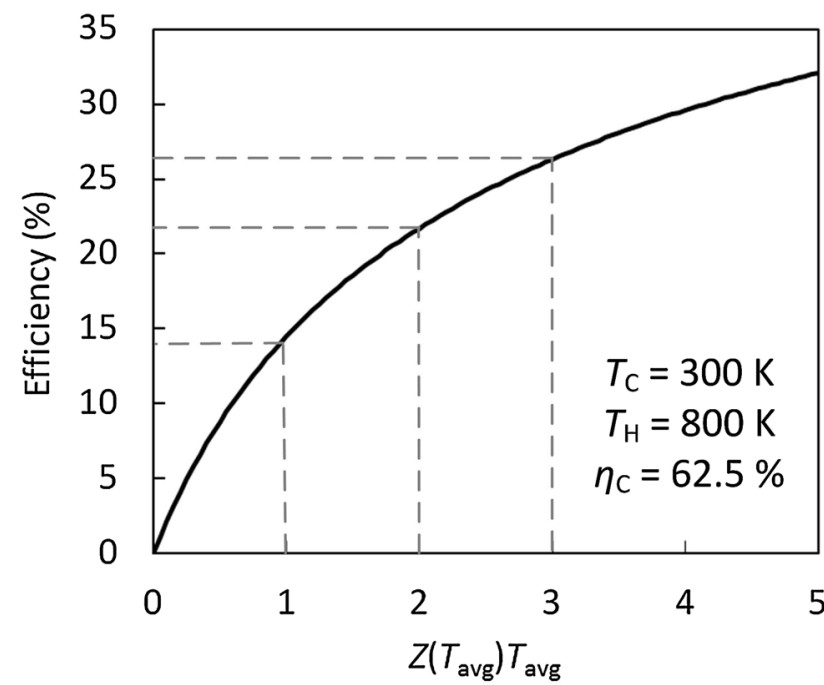

Fig. 9. Energy conversion efficiency as a function of $Z T_{\text {avg }}$ using the constant property model. The cold side temperature is $300 \mathrm{~K}$ and the hot side temperature is $800 \mathrm{~K}$. The Carnot efficiency for this temperature difference is $62.5 \%$. than the temperature dependence of the material properties. We note that the highest average $Z T$ for the materials and temperature differences studied in this work is 1.4 , and most materials have average $Z T<1$ (Table I).

\section{CONCLUSIONS}

The adequacy of the conventional dimensionless thermoelectric figure of merit $Z T$, which has historically played a central role in both device design and materials selection for thermoelectric power generation applications, was recently questioned, and an alternative average property model was proposed. ${ }^{11}$ An evaluation in the present work of the energy conversion efficiencies predicted by the conventional constant property model and the average property model for 18 high performance thermoelectric materials confirms that the conventional constant property model typically over-estimates the efficiency in comparison to the average property model, on 
average by a factor of 1.16 (excluding $\operatorname{In}_{4} \mathrm{Se}_{2.35}$ ) for the largest temperature differences evaluated. Both models will overestimate the efficiency in comparison to real device efficiencies, thus their usefulness lies in providing simple metrics for new materials evaluation, comparison, and materials selection. We, therefore, conclude that although $(Z T)_{\text {eng }}$ uniformly comprises a more conservative metric for evaluating new materials, the advantage in many cases is relatively small, and conventional $Z T$ can likely still be used as a simple and useful metric for initial materials evaluation. However, the conventional $Z T$ needs to be used appropriately, keeping in mind that it is the average $Z T$, not peak $Z T$, that should be used to estimate material energy conversion efficiency in the simpler constant property model. Although rarely reported in studies of new thermoelectric materials, the average $Z T$ for a given temperature range is easily obtained and provides a better metric than peak $Z T$ in materials selection. Inclusion of the calculated $Z T$ at $T_{\text {avg }}$ for the potential temperature range of operation is therefore recommended in future materials investigations, along with a comparison of this quantity with that of other known thermoelectric materials in the same potential temperature range of operation.

\section{ACKNOWLEDGEMENTS}

MB would like to acknowledge R. McClure for support and encouragement in carrying out this project.

\section{REFERENCES}

1. L.E. Bell, Science 321, 1457 (2008).

2. E. Altenkirch, Physikalische Zeitschrift 10, 560 (1909).

3. A.F. Ioffe, Semiconductor Thermoelements and Thermoelectric Cooling (London: Infosearch, 1957).

4. G.S. Nolas, J. Sharp, and H.J. Goldsmid, Thermoelectrics, Basic Principles and New Materials Developments (Berlin: Springer, 2001).

5. T.M. Tritt and M.A. Subramanian, MRS Bull. 31, 188 (2006).

6. G.D. Mahan, J. Appl. Phys. 70, 4551 (1991).

7. T.P. Hogan and T. Shih, Thermoelectrics Handbook: Macro to Nano, ed. D.M. Rowe (Boca Raton: CRC Press, 2006), p. 12-1.

8. D. Ebling, M. Jaegle, M. Bartel, A. Jacquot, and H. Böttner, J. Electron. Mater. 38, 1456 (2009).

9. G.J. Snyder, Thermoelectrics Handbook: Macro to Nano, ed. D.M. Rowe (Boca Raton: CRC Press, 2006), p. 9-1.

10. J. Yang and T. Caillat, MRS Bull. 31, 224 (2006).
11. H.S. Kim, W. Liu, G. Chen, C.-W. Chu, and Z. Ren, Proc. Natl. Acad. Sci. USA 112, 8205 (2015).

12. L.-D. Zhao, S.-H. Lo, Y. Zhang, H. Sun, G. Tan, C. Uher, C. Wolverton, V.P. Dravid, and M.G. Kanatzidis, Nature 508, 373 (2014).

13. J.-S. Rhyee, K.H. Lee, S.M. Lee, E. Cho, S.I. Kim, E. Lee, Y.S. Kwon, J.H. Shim, and G. Kotliar, Nature 459, 965 (2009).

14. H.J. Goldsmid, Introduction to Thermoelectricity (Berlin: Springer, 2010).

15. J.R. Salvador, J.Y. Cho, Z. Ye, J.E. Moczygemba, A.J. Thompson, J.W. Sharp, J.D. Koenig, R. Maloney, T. Thompson, J. Sakamoto, H. Wang, and A.A. Wereszczak, Phys. Chem. Chem. Phys. 16, 12510 (2014).

16. K.F. Hsu, S. Loo, F. Guo, W. Chen, J.S. Dyck, C. Uher, T. Hogan, E.K. Polychroniadis, and M.G. Kanatzidis, Science 303,818 (2004).

17. S. Deng, Y. Saiga, K. Kajisa, and T. Takabatake, J. Appl. Phys. 109, 103704 (2011).

18. X. Shi, J. Yang, J.R. Salvador, M. Chi, J.Y. Cho, H. Wang, S. Bai, J. Yang, W. Zhang, and L. Chen, J. Am. Chem. Soc. 133, 7837 (2011)

19. B. Poudel, Q. Hao, Y. Ma, Y. Lan, A. Minnich, B. Yu, X. Yan, D. Wang, A. Muto, D. Vashaee, X. Chen, J. Liu, M.S. Dresselhaus, G. Chen, and Z. Ren, Science 320, 634 (2008).

20. R. Funahashi and M. Shikano, Appl. Phys. Lett. 81, 1459 (2002).

21. X. Lu, D.T. Morelli, Y. Xia, and V. Ozolins, Chem. Mater. 27, 408 (2015).

22. H. Liu, X. Shi, F. Xu, L. Zhang, W. Zhang, L. Chen, Q. Li, C. Uher, T. Day, and G. Jeffrey Snyder, Nat. Mater. 11, 422 (2012).

23. C. Fu, S. Bai, Y. Liu, Y. Tang, L. Chen, X. Zhao, and T. Zhu, Nat. Commun. 6, 1 (2015).

24. R. He, H.S. Kim, Y. Lan, D. Wang, S. Chen, and Z. Ren, RSC Adv. 4, 6471 (2014).

25. A.F. May, J.-P. Fleurial, and G.J. Snyder, Phys. Rev. B 78, 125205 (2008).

26. Q. Zhang, J. He, T.J. Zhu, S.N. Zhang, X.B. Zhao, and T.M. Tritt, Appl. Phys. Lett. 93, 102109 (2008).

27. Y. Pei, X. Shi, A. LaLonde, H. Wang, L. Chen, and G.J. Snyder, Nature 473, 66 (2011).

28. C.B. Vining, W. Laskow, J.O. Hanson, R.R. Van der Beck, and P.D. Gorsuch, J. Appl. Phys. 68, 4333 (1991).

29. K. Biswas, J. He, I.D. Blum, C.-I. Wu, T.P. Hogan, D.N. Seidman, V.P. Dravid, and M.G. Kanatzidis, Nature 489, 414 (2012).

30. S.R. Brown, S.M. Kauzlarich, F. Gascoin, and G.J. Snyder, Chem. Mater. 18, 1873 (2006).

31. T. Caillet, J.-P. Fleurial, and A. Borshchevsky, J. Phys. Chem. Solids 58, 1119 (1997).

32. A. Rohatgi, WebPlotDigitizer 3.9. (WebPlotDigitizer, 2016), http://arohatgi.info/WebPlotDigitizer. Accessed 15 May 2016.

33. T.M. Tritt, X. Feng, Q. Zhang, and W. Xie, Fundamentals of Materials for Energy and Environmental Sustainability (Cambridge: Cambridge University Press, 2012), p. 289. 